\title{
Fear of falls among nursing homes residents and community dwelling elderly
}

\author{
Motassem S. Amer, Asmaa F. Abdellah, Eman S. Elsayed* \\ Department of Geriatrics and Gerontology, Faculty of Medicine, Ain shams university, Cairo, Egypt \\ *Corresponding author: Eman S. Elsayed, Email: emansaad432@ gmaill.com, Tel.: 01025438118
}

\begin{abstract}
Background: fear of falling is common among elderly faller and it has been associated with impaired mobility and decreased functional status. As a result, older adults who have fallen are at greater risk of becoming institutionalized regardless of whether they have experienced an injurious fall.

Objectives: the aim of the study is to assess the prevalence of fear of falls in elderly in geriatric home and in community dwelling elderly.

Subjects and Methods:

Design: A comparative study.

Participants: 100 resident in nursing homes in Cairo and another 100 in community.

Measurements: comprehensive geriatric assessment (CGA) including Minimental status examination (MMSE-30), Geriatric Depression scale (GDS-15), Mininutritional assessment (MNA), time up and go test (TUGT), activity of daily living (ADL), instrumental activity of daily living (IADl), Single item question "are you afraid of falling?"
\end{abstract}

Results: the study showed that the prevalence of fear of falls in elderly living in nursing homes in Cairo is higher than others living in community, also showed that a higher percentage of environmental factors of falling among elderly in nursing homes compared to community, higher percentage of elderly with risk of fall living in nursing homes.

Conclusion: prevalence of fear of falls is higher in elderly living in nursing homes in Cairo than others living in community.

Keywords: falls, fear of falls, elderly, community, geriatric homes

\section{Introduction}

Older people make up a large and increasing percentage of the population of countries worldwide. As people grow older they are increasingly at risk of falling and suffering injury from falling ${ }^{(\mathbf{1})}$.

Upon aging there is a progressive decrease in functional capacity, verified by reduced strength of lower limbs, impaired balance and agility. Such changes may impact a patient's daily activities such as climbing and descending stairs or siting and standing up from a chair, besides reducing the ability of the elderly to promptly respond to external disturbances, such as slipping and stumbling, and to restore balance ${ }^{(2)}$.

Fear of falling (FOF) is a major health problem among the elderly living in communities, present in older people who have fallen but also in older people who have never experienced a fall. An estimated 30-55\% of older persons acknowledge being afraid of falling, and approximately one third of them report restricting their activities. FOF has gained recognition as a specific health problem among older adults. The reported prevalence of FOF varied between $3-85 \%{ }^{(3)}$. However, when FOF results in avoidance of activities and reduction of physical fitness, it is a risk factor for future falls and associated mortality, dysfunctioning, and premature nursing home admissions ${ }^{(3)}$.

FOF is defined as an exaggerated concern about falls or the belief that one cannot prevent a fall. Intense anxiety about falls can be experienced by older adults who have fallen, as well as those who have not. Although studies have shown that women are at an elevated risk, fear of falls affects both men and women ${ }^{(4)}$.

FOF and activity avoidance may result in social isolation and inactivity, and threatens the quality of life if preventive measures are not taken in immediate future, the numbers of injuries caused by falls is projected to be $100 \%$ higher in the year $2030^{(5)}$.

Fear of falling may be a reasonable response to certain situations, that may lead elderly persons to be cautious, and can contribute to fall 
prevention through careful choices about physical activity so, fear rep-resents a reasonable reaction to possible danger and has few negative consequences as long as physical and social mobility remains unaffected. However, the fear of falling can initially present or progress be-yond this point to become a debilitating condition ${ }^{(6)}$.

\section{Subjects and Methods: \\ Study design:}

A comparative study conducted to assess the prevalence of fear of falls in elderly in geriatric homes and in community dwelling elderly.

This study was approved by Ethical Committee of faculty of Ain Shams University.

\section{Selection of Subjects}

Sample size: 100 resident in nursing homes in Cairo and another 100 in community.

\section{Selection of subjects:}

- Aged 60 years or more.

- All subjects agreed to participate in the study were included.

\section{Exclusion:}

- Refusal of participation.

- Severe dementia. Severe depression.

- Immobile elderly.

- Assessment:
The following procedures were done for all subjects:

1. Informed consent.

2. Minimental status examination (MMSE-30) (7).

3. Geriatric Depression scale (GDS-15) ${ }^{(8)}$.

4. Mininutritional assessment (MNA) ${ }^{(9)}$.

5. Time up and go test (TUGT) ${ }^{(10)}$.

6. $\operatorname{ADL}^{(11)}$.

7. $\operatorname{IADL}^{(12)}$.

8. Single item question "are you afraid of falling" (13)

Statistical analysis: The data was collected, coded and entered to a personal computer (P.C.) IBM compatible. The data was analyzed with the program (SPSS) statistical package for social science under windows version 15.0.

The statistical tests used in this thesis are:

1- Student $t$ test:

2- Chi- square test $\left(\mathrm{X}^{2}\right)$

3- One way analysis of variance (ANOVA):

4- Bonferoni post hoc test:

A p-value less than 0.05 is considered a significant statistical difference.

\section{Results}

A higher percentage of elderly in nursing homes were afraid of falling $58 \%$ compared to $27 \%$ among community dwellers (Tab 1).

Tab (1): Comparison between elderly in nursing homes and community dwellers as regards the fear of falling by a single question (are you afraid of falling?).

\begin{tabular}{|l|c|c|c|c|}
\hline Are you afraid of falling? & $\begin{array}{c}\text { No } \\
\text { No. \% }\end{array}$ & $\begin{array}{c}\text { Yes } \\
\text { No. \% }\end{array}$ & X2 & \multirow{2}{*}{ P } \\
\hline Elderly in community N=100 & 73 73.0 & $27 \quad 27.0$ & \multirow{2}{*}{19.6} & \multirow{2}{*}{$\mathbf{0 . 0 0 1 * *}$} \\
\hline Elderly in nursing homes N=100 & 4242.0 & $58 \quad \mathbf{5 8 . 0}$ & \\
\hline
\end{tabular}

This table shows that a higher percentage of elderly in nursing homes were afraid of falling $58 \%$ compared to $27 \%$ among community dwellers and the difference is highly significant statistically.

higher percentage of environmental factors of falling among elderly in nursing homes compared to community dwellers (Tab 2).

Tab (2): Comparison between elderly in nursing homes and community dwellers as regards circumstances of previous falling.

\begin{tabular}{|l|cc|cc|c|c|}
\hline $\begin{array}{l}\text { Circumstances of previous } \\
\text { falling }\end{array}$ & \multicolumn{2}{|c|}{$\begin{array}{c}\text { Community } \\
\text { N=100 }\end{array}$} & \multicolumn{2}{|c|}{$\begin{array}{c}\text { Nursing homes } \\
\text { N=100 }\end{array}$} & X2 & P \\
\hline No. \% & No. $\%$ & & \\
\hline Environmental factors & 10 & 10.0 & $\mathbf{2 7}$ & $\mathbf{2 7 . 0}$ & 9.5 & $\mathbf{0 . 0 0 2} * *$ \\
\hline Hospical & 5 & 5.0 & 8 & 8.0 & 0.7 & 0.3 \\
\hline Vision problems & 2 & 2.0 & 17 & $\mathbf{1 7 . 0}$ & 13.0 & $\mathbf{0 . 0 0 0} * *$ \\
\hline Hearing problems & 16 & 16.0 & $\mathbf{3 3}$ & $\mathbf{3 3 . 0}$ & 7.8 & $\mathbf{0 . 0 0 5} * *$ \\
\hline Vestibulocerebral insufficiency & 6 & 6.0 & 12 & 12.0 & 2.1 & 0.1 \\
\hline
\end{tabular}

This table shows that a higher percentage of environmental factors of falling, higher percentage of previous hospitalization and problems of vision among elderly in nursing homes compared to community dwellers and the difference is highly significant statistically. And higher percentage of elderly with risk of fall living in nursing homes $52 \%$ compared to $27 \%$ in the community (Tab 3). 
Table (3): Comparison between elderly in community and in nursing homes as regards risk of falls by the time up and go test TUGT.

\begin{tabular}{|c|c|c|c|c|}
\hline Time up and go test & \begin{tabular}{c}
\multicolumn{2}{c}{ Normal } \\
No. $\%$
\end{tabular} & $\begin{array}{l}\text { At risk } \\
\text { No. } \%\end{array}$ & $\mathbf{X} 2$ & $\mathbf{P}$ \\
\hline Elderly in community $\mathrm{N}=100$ & $\begin{array}{ll}73 & 73.0 \\
\end{array}$ & $27 \quad 27.0$ & & \\
\hline $\begin{array}{l}\text { Elderly in nursing homes } \\
\mathrm{N}=100\end{array}$ & $48 \quad 48.0$ & $52 \quad \mathbf{5 2 . 0}$ & 13.0 & $0.001 * *$ \\
\hline
\end{tabular}

Higher percentage of elderly with risk of fall living in nursing homes was $52 \%$ compared to $27 \%$ in the community and the difference is highly significant statistically.

\section{Discussion}

The result in current study shows that a higher percentage of elderly in nursing homes were afraid of falling $58 \%$ compared to $27 \%$ among community dwellers Kumar et al. ${ }^{(14)}$ in their study in 1,088 community-dweller found that prevalence of fear of falls was $19 \%$. Cronin $\boldsymbol{e t}$ $\boldsymbol{a l}^{(15)}$ in their study in 4914 community-dweller found that prevalence of fear of falls was 23.3\%. Gillespie et $\boldsymbol{a l}$. $^{(16)}$ in their study of 112 new enrollees in LTC programs in New York found that prevalence of fear of falls was $48.2 \%$. As regard circumstances of previous falling higher percentage of environmental factors of fear of falling among elderly in nursing homes compared to community dwellers and the difference is highly significant statistically. This calls attention to the importance of home safety for prevention of fear of falls

Higher percentage of problems of vision among elderly in nursing homes compared to community dwellers and the difference is highly significant statistically. This calls the attention for visual correction for prevention of fear of falls. Our result agrees with Murphy $\boldsymbol{e t}$ al. (17) in their study that found visual impairment associated with fear of falls.

The result in the current study shows that higher percentage of elderly with risk of fall living in nursing homes was $52 \%$ compared to $27 \%$ in the community. Also higher fear of falling presents among elderly with risk of falls than elderly with no risk of falls. Our result agree with the study of Lee $\boldsymbol{e t}$ al. ${ }^{(18)}$ in their study in Korea in their study Who reported that the more people who at risk of falls by time up and go test the more fear of falls as falls is predisposing factor for fear of falls.

\section{Acknowledgment}

All authors contributed to the work and there are no areas of conflict. No sponsors to the work.

\section{References}

1-Rubenstein LZ (2006): Falls in older people: epidemiology, risk factors and strategies for prevention. Age and Ageing, 35(2):37-41.

2-Bento PC, Pereira G, Ugrinowitsch C and Rodacki AL (2010): Peak torque and rate of torque development in elderly with and without fall history. Clin Biomech (Bristol, Avon), 25(5):450-454

3- Fabricio SC, Rodrigues RA and Costa ML (2004): Junior Causes and consequences of falls of elderly people attended in a public hospital. Public Health Rev., 38(1):93-99.

4- Centers for Disease Control and Prevention CDC (2016): National Center for Injury Prevention and Control Important Facts about Falls From.

https://www.cdc.gov/homeandrecreati onalsafety/falls/adultfalls.html

5- Ribeiro AP, Souza ER, Atie S et al (2008): The influence of falls on the quality of life of the elderly,13(4):1265-1273.

6-Jung D (2008): Fear of falling in older adults: Comprehensive review. Asian Nursing Research, 2(4), 214-222.

7-Folstein MF, Folstein SE and McHug PR (1975): Minimental state. A practical method for gradient the cognitive state of patients for clinicians. J Psychiat. Res., 12-189.

8- Wancata J, Alexandrowicz R, Marquart B et al. (2006): The criterion validity of the Geriatric Depression Scale: a systematic review. ActaPsychiatrScand ,114(6):398-410

9- Guigoz Y, Vellas B and Garry PJ (1996): Assessing the nutritional status of the elderly: The mini nutritional assessment as part of the geriatric evaluation. Nutr Rev., 54:S59-S65.

10- Podsiadlo $D$ and Richardson $S$ (1991) :The timed "Up \& Go": a test of 
basic functional mobility for frail elderly persons. J Am GeriatrSoc., 39:142-8

11- Katz S, Ford AB, Moswowitz RWet al. ( 1963): Studies of illness in the aged. The index of ADL: Standardized measure of biological and psychological function, JAMA., 185914.

12- Lawton MP and Brody EM (1969): Assessment of older people: Selfmaintaining and instrumental activities of daily living. The Gerontologist, 9(3):179-86.

13- Cameron I.E, Stafford B, Cumming RG et al. (2000): Hip protectors improve falls self-efficacy. Age and Ageing, 29, 57-62.

14- Kumar A, Carpenter H, Morris $\mathrm{R}$ et al. (2014): Which factors are associated with fear of falling in community-dwelling older people?, Age and Ageing,43(1): 76-84.
15- Cronin H, Savva G, O'regan, C et al. (2013): Fear Of Falling In An Older Irish Population. Age and Ageing, 42(2): 20-22.

16- Gillespie SM and Friedman SM (2007): Fear of falling in new longterm care enrollees. Journal of the. American Medical Directors Association, 8(5), 307-313.

17- Murphy S L, Dubin J A and Gill TM (2003) :The development of fear of falling among community-living older women: predisposing factors and subsequent fall events. The Journals of Gerontology Series A: Biological Sciences and Medical Sciences, 58(10): M943-M947.

18- Lee J, Choi M and Kim C (2017): Falls, a Fear of Falling, and related Factors in Older Adults with Complex Chronic Disease. Journal of Clinical Nursing,22:61-93. 